\title{
Farinha de caramujo africano (Achatina fulica Bowdich, 1822) como possível fonte de proteína em nutrição animal
}

\author{
African snail flour (Achatina fulica Bowdich, 1822) as a possible source of protein in animal \\ nutrition
}

Farina de caracol africana (Achatina fulica Bowdich, 1822) como posible fuente de proteína en la nutrición animal

\section{Resumo}

O caramujo gigante africano Achatina fulica foi introduzido no Brasil na década de 80, como alimentação humana, para substituir o escargot francês, sem que houvesse nem um estudo de mercado. Com o fracasso, os animais foram soltos no ambiente sem preocupação com o impacto que ele causaria. Trata-se de uma espécie prolífera, botando de 200 a 400 ovos em cada postura, quatro a seis vezes ao ano. O impacto ambiental que a espécie causa é predar plantas, competir por espaço com outras espécies e agir como vetor de dois vermes que transmitem doenças. Com essas informações, o objetivo desse trabalho foi elaborar uma farinha de caramujo, caracterizando a composição bromatológica e parâmetros microbiológicos, para utilizar como fonte proteica em nutrição animal. A farinha de caramujo apresenta pouco rendimento $(7,42 \%)$, porém alto valor nutricional. As análises microbiológicas da farinha de carne do caramujo indicam que os processamentos tecnológicos adotados neste trabalho (dieta hídrica, abate, manipulação, embalagem), parecem ser viáveis para a obtenção de farinha de carne em relação à qualidade sanitária. Com base nesses resultados, a carne do Caramujo-Gigante-Africano apresenta potencial como matéria prima na utilização de ração animal.

Palavras-chave: Alimento proteico; Impacto ambiental; Nutrição.

\begin{abstract}
The giant African snail Achatina fulica was introduced in Brazil in the 80s, as human food, to replace the French escargot, without even a market study. With the failure, the animals were released into the environment without concern for the impact it would cause. It is a prolific species, laying 200 to 400 eggs in each posture, four to six times a year. The environmental impact that the species causes is to prey on plants, compete for space with other species and act as a vector of two worms that transmit diseases. With this information, the objective of this work was to elaborate a snail meal, characterizing the chemical composition to be used as a protein source in animal nutrition. The snail flour has little yield (7.42\%), but high nutritional value. Microbiological analyzes of the snail meat meal indicate that the technological processes adopted in this work (water diet, slaughter, handling, packaging) seem to be viable to obtain meat meal in relation to sanitary quality. Based on these results, the meat of the Giant-African-Snail has potential as a raw material in the use of animal feed.
\end{abstract}

Keywords: Environmental impact; Nutrition; Protein food. 


\begin{abstract}
Resumen
El caracol gigante africano Achatina fulica fue introducido en Brasil en los años 80, como alimento humano, para reemplazar al caracol francés, sin ni siquiera un estudio de mercado. Con la falla, los animales fueron liberados al medio ambiente sin preocuparse por el impacto que causaría. Es una especie prolífica, que pone de 200 a 400 huevos en cada postura, cuatro a seis veces al año. El impacto ambiental que provoca la especie es depredar plantas, competir por espacio con otras especies y actuar como vector de dos gusanos transmisores de enfermedades. Con esta información, El objetivo de este trabajo fue elaborar una harina de caracol, caracterizando la composición química y los parámetros microbiológicos para ser utilizada como fuente de proteínas en la nutrición animal. La harina de caracol tiene poco rendimiento $(7,42 \%)$, pero alto valor nutricional. Los análisis microbiológicos de la harina de carne de caracol indican que los procesos tecnológicos adoptados en este trabajo (dieta de agua, sacrificio, manipulación, envasado) parecen viables para obtener harina de carne en relación a la calidad sanitaria. Con base en estos resultados, la carne del Caracol-Gigante-Africano tiene potencial como materia prima en el uso de alimentos para animales.
\end{abstract}

Palabras clave: Alimentos proteicos; Nutrición; Impacto ambiental.

\title{
1. Introdução
}

Os caramujos são gastrópodes possuidores de características que os definem como animais de corpo mole, inteiriço, com cabeça e patas que se confundem com o ventre e cujas vísceras se localizam na parte superior, tudo protegido pela concha helicoidal (Ferraz, 1999). Representante desse grupo e pertencente à família Achatinidae, Achatina fulica Bowdich, 1822 é uma espécie de caramujo terrestre pulmonado, originário do Leste da África, com distribuição que vem se expandindo desde o século XIX, potencializada por interesses humanos (Kotangale, 2011). Ocorre em pelo menos 43 países, distribuídos em praticamente todos os continentes por causa de introduções voluntárias (Leão et al., 2011; Fontanilla et al., 2014). Se espalhou por localidades na América do Norte e Europa e por diversos países tropicais e subtropicais Indo-Pacíficos nos últimos 200 $\operatorname{anos}($ Rees, 1950).

O molusco foi introduzido no Brasil, onde é conhecido como Acatina, Caracol-Gigante-Africano, Caracol-Gigante, Caracol-Africano, Caramujo Gigante, Caramujo-Gigante-Africano e Rainha-da-África (Rodrigues et al, 2007), na década de 1980 como um substituto da criação de escargot, sem que houvesse qualquer estudo de mercado, verificação de experiências análogas em outros países ou autorização do órgão competente. O resultado é que a comercialização foi um fracasso, levando ao abandono de criadouros e à soltura dos caracóis no ambiente. Atualmente, o Caracol-Gigante-Africano já ocorre em pelo menos 23 dos 26 estados brasileiros (Thiengo et al., 2007).

A espécie Achatina fulica tem sido considerada o caramujo africano mais introduzido, com maior amplitude de invasão e a principal praga entre os caracóis (Raut \& Barker, 2002). Além disso, é considerado uma das 100 piores espécies invasoras do mundo (Lowe et al., 2000)

Os indivíduos adultos de A. fulica podem atingir uma massa de mais de $200 \mathrm{~g}$ e chegar a $15 \mathrm{~cm}$ de comprimento de concha. No Estado de São Paulo os valores máximos encontrados foram ao redor de 100 gramas de massa e $10 \mathrm{~cm}$ de comprimento de concha (Paiva, 2006). É um caramujo de concha cônica marrom ou mosqueada, que alcança a maturidade sexual entre quatro e cinco meses. Os indivíduos são hermafroditas e prolíferos, botando de 200 a 400 ovos em cada postura, que ocorre de quatro a seis vezes ao ano (Moreira, 2014). Ativo no inverno, resistente ao frio e à seca, geralmente passa o dia escondido e sai para se alimentar e reproduzir à noite ou, durante e logo após as chuvas (Paiva, 2006; Instituto Hórus, 2006).

Os impactos causados por esse caramujo se refletem na predação de plantas e competição por espaço com outras espécies, em função do aumento populacional acelerado. A espécie ataca praticamente qualquer lavoura, causando prejuízos econômicos, além de também competir com espécies nativas em ambientes florestais. É vetor de dois vermes que transmitem doenças: Angiostrongylus costaricensis, causador da angiostrongilíase abdominal; e Angiostrongylus cantonensis, causador da angiostrongilíase meningoencefálica humana (CABI, 2010; Leão et al, 2011; Carvalho \& Omena, 2014).

Estudos comprovam que Caracol-Gigante-Africano pode se infectar naturalmente por vermes que são transmitidos aos humanos por meio de alimentos mal lavados e podem causar grave infecção intestinal e meningite (Caldera et al., 2007; 
Graeff-Teixeira, 2007). Uma alternativa de redução da infestação poderia ser a produção de farinha de caramujo para a alimentação animal, a qual quando comparada com outros métodos parece produzir menos desperdícios adicionais. A farinha de pescado em geral é produzida no mundo a partir de pequenos peixes pelágicos como anchova e seu preço varia de acordo com o teor de proteínas (Yano et al, 2008).

A aquicultura é a principal consumidora deste produto e simulações bioeconômicas a curto prazo realizados por Merino, Barange e Mullon (2010), sugerem que se a aquicultura continuar a se expandir e depender do consumo de farinha de peixe, a produção de peixes pelágicos se tornará crítica, com consequências na produção global para consumo humano.

A carne do Achatina fulica apresenta elevados valores de $\mathrm{pH}$, que variam de 7,89 (in natura) a 8,4 (enlatado) e baixos níveis de lipídios (0,63 a 0,92). Em componentes minerais e aminoácidos, possui elevados valores de Ca, Mg, Zn e Fe (cálcio, magnésio, zinco e ferro), associados à disponibilidade de ácido aspártico, ácido glutâmico e leucina, entre outros (Oeterher, 1996). O muco liberado pelos moluscos é um fluido elástico resultante da mistura da secreção de várias glândulas sendo que suas principais funções são: agir como veículo de transporte das partículas da superfície ciliada; secretar produtos; transferir água e eletrólitos através da epiderme e auxiliar na locomoção (Lorenzi, 2006). Alterações da pressão sanguínea permitem a liberação de muco na locomoção ou nas fibras musculares, controladas nervosas ou endocrinamente e dispostas ao redor das glândulas que levam à liberação do muco quando contraem (Campion, 1961).

Aquino (2013) realizou a composição centesimal do muco do caracol Achatina fulica e obteve os seguintes dados: matéria seca $(91,72 \% \pm 1,85)$, umidade $(8,28 \% \pm 0,97)$, cinzas $(31,1 \% \pm 0,35)$, proteína bruta $(49,97 \% \pm 3,21)$, carboidratos $(8,15 \% \pm 1,43)$, calorias totais $(242,48 \pm 53,23)$, lipídeos em $100 \mathrm{~g}(2,5 \pm 0,44)$ e colesterol $(50,2 \pm 0,3)$; o muco não demonstrou capacidade antioxidante em nenhuma das amostras analisadas.

\subsection{Alimentação proteica de animais}

A alimentação é um dos principais fatores no custo de produção animal, sendo que entre seus componentes, os alimentos proteicos são os mais onerosos. Dessa forma, a determinação da exigência proteica implica em redução de custos. Considerando-se a possibilidade de obter bons índices de conversão alimentar com o uso de dieta completa (Ribas, 1986; Soares et al. 1999; Ferraz, 1999; Hayashi et al., 2000), a determinação do nível adequado de proteína é importante para melhor aproveitamento alimentar e racionalização de custos de produção. Com o crescimento exponencial da Aquicultura, a demanda por alimento inerte também aumenta, principalmente na área da piscicultura e carcinicultura. A utilização de ração de alto valor proteico é essencial nas dietas de peixes e camarões.

A maioria dos peixes alimentados em cultivos contém um nível mínimo de farinha de peixe, a fim de garantir um ótimo teor de aminoácidos e outros nutrientes necessários para o crescimento dos peixes e qualidade da carne. Entretanto, o uso de produtos derivados do peixe em fórmulas de alimentos pode representar um dilema, acerca da possibilidade desse peixe ser utilizado como alimento humano. Se forem necessários menos de um quilograma de peixe na alimentação para produzir um quilo de peixes de viveiro, seria mais aceitável. Progressivamente menos farinha e óleo de peixe estão sendo utilizados para a aquicultura, apesar de seu constante aumento de produção. Para reduzir os custos de produção, são utilizadas alternativas mais baratas como os vegetais substituindo cada vez mais o óleo de peixe (FAO, 2014). Os alimentos de origem animal usados na elaboração de ração balanceada apresentam proteína de alto valor biológico. A tendência é sempre que possível elaborar ração com ingredientes de origem vegetal, por motivos econômicos e pela grande quantidade desse produto em oferta (Rebelo Neto, 2013).

Contudo, os produtos de origem vegetal na maioria das vezes não possuem quantidade e qualidade de proteína e aminoácido requeridos, além de apresentar baixo índice de minerais e conter produtos com efeitos antinutricionais. Por esse motivo, quase sempre é necessário a adição de produtos animais (Rebelo Neto, 2013). Dioumande et al. (2008) introduziram a 
farinha de caramujo (Achatina fulica) como uma importante fonte de proteína e como alimento barato em dieta de frango de corte na Costa do Marfim e indicam na dieta para frango inicial, a substituição de 3\% em relação à farinha de peixe. Já para fase de crescimento, a substituição de $10 \%$ em relação à farinha de peixe, sem afetar as características sensoriais da carne do frango. Neste contexto, este trabalho objetivou elaborar e caracterizar nutricionalmente a farinha de Caramujo-GiganteAfricano e analisar sua viabilidade nutricional como fonte de proteína em nutrição animal.

\section{Metodologia}

\subsection{Tipo de Pesquisa}

Essa é uma pesquisa que se utilizou de coleta de amostras em campo, as quais foram transportadas aos laboratórios para realização dos demais procedimentos, descritos detalhadamente nos tópicos abaixo. Tais procedimentos culminaram na obtenção de dados quantitativos e qualitativos, que permitiram a caracterização da farinha de caramujo obtida.

\subsection{Amostra e área amostral}

Foi utilizada a espécie Achatina fulica, 88 exemplares vivos foram colhidos manualmente de terrenos residenciais durante o período chuvoso na localidade de Terra Alta - PA, com Latitude $01^{\circ} 02^{\prime} 28^{\prime \prime}$ 'Sul e Longitude 47 54' 27" Oeste, localizada a $100 \mathrm{~km}$ da capital Belém - PA. A condição ambiental dessa região é dada como clima tropical, a classificação do clima é Am, de acordo com Köppen e Geiger. O município tem uma temperatura média de $26,6^{\circ} \mathrm{C}$, pluviosidade média anual de $2538 \mathrm{~mm}$, regime chuvoso distribuído em duas épocas com altitude de 40 m (CLIMATE, 2021).

\subsection{Extração da carne do caramujo}

Para a extração da carne do caramujo os animais foram armazenados durante 72 horas sem acesso a alimentação em caixa plástica $(49 \mathrm{~cm}$ x $30 \mathrm{~cm}$ x $09 \mathrm{~cm}$ ) com tampa ventilada e capacidade de até três quilos. Durante este período os animais foram hidratados com água para que não houvesse mortalidade. Esse jejum foi feito para esvaziar o trato digestivo dos indivíduos, objetivando diminuir a contaminação microbiana do produto final.

Ao final de 72 horas os animais foram lavados com água clorada a 5pm para que fossem retiradas por completo as fezes dos animais e em seguida foi removido o excesso de água para dar início a extração da "baba" ou muco, mediante movimento circulatório nas glândulas anexas ao orifício anal e respiratório, utilizando um palito de madeira. Lorenzi (2006) orientam pressionar o polegar contra as glândulas podais para estimulá-las. Devido à manipulação dos animais nessa fase de extração, eles se tornam fracos e susceptíveis a adquirir doenças.

Após extração da baba, os caracóis foram lavados e escorridos, separou-se 4,4\% do total de caracóis, quantidade suficiente para fazer análise microbiológica. Os espécimes foram então imersos em água com gelo durante 20 minutos, em seguida foi realizada a extração da carne in natura, que foi acondicionada em sacos plástico e armazenada sob temperatura de congelamento. Os exemplares restantes foram abatidos numa solução de água fervente, a uma concentração de $0,7 \%$ de sal comum durante 15 minutos. Utilizou-se uma proporção de 2 litros de água para $3 \mathrm{~kg}$ de caracóis, de acordo com Cabezas García et al. (2011). Enquanto fervia, o excesso de muco restante não extraído foi separado.

Ao final de 15 minutos, os caracóis foram dispostos em um escorredor de alumínio para uma nova lavagem com água clorada a 5pm e em seguida, foram colocados em um balde com água e gelo durante 5 minutos para facilitar a extração da carne. Cada caramujo foi punçado, com um garfo de duas pontas, perto do orifício respiratório e posteriormente era girado à direita até um ângulo de $270^{\circ}$, procurando tirar por completo a carne sem deixar resíduos na concha. As conchas foram consideradas como resíduo (material de descarte).

A carne obtida foi escorrida, para tirar o excesso de água, e embalada em filme de PVC transparente. O produto foi 
congelado em freezer e armazenado até o momento de obtenção da farinha, e posterior cálculo do rendimento, utilizando as seguintes etapas: animal vivo (em pé); em jejum; animal vivo sem baba (muco); animal morto após tratamento térmico; animal sem a concha cozido e farinha de carne.

\subsection{Elaboração da farinha}

A carne de caramujo foi descongelada à temperatura ambiente de $\pm 26^{\circ} \mathrm{C}$, disposta homogeneamente em bandejas metálicas e então levada para a secagem em estufa com circulação e renovação de ar (TE - 394/1 TECNAL) por 72 horas a uma temperatura de $55{ }^{\circ} \mathrm{C}$. Enquanto o produto permaneceu na estufa, a cada 12 horas o material foi movimentado com o intuito de garantir uma secagem homogênea. Ao final da secagem, o material foi triturado em um moinho de facas tipo Willye (TE - 650 TECNAL) e o material triturado foi peneirado, utilizando-se uma peneira de $1 \mathrm{~mm}$. A farinha obtida foi armazenada em sacos de 200g até o momento da determinação da composição centesimal.

\subsection{Análise microbiológica}

A carne in natura e a carne cozida foram submetidas a determinações de contagem de Enterobacterias. A farinha obtida foi submetida a determinações de coliformes totais e fecais e pesquisa de Salmonella de acordo com a Instrução Normativa $\mathrm{n}^{\circ} 62$ do MAPA (2003). As análises foram realizadas no Laboratório de Higiene e Qualidade de Alimentos da Universidade Federal do Pará - Campus Castanhal, Faculdade de Medicina Veterinária.

\subsubsection{Contagem de enterobactérias}

Foram utilizadas $25 \mathrm{~g}$ das amostras (in natura e cozida) em erlenmeyer contendo $225 \mathrm{ml}$ de água destilada estéril sendo homogeneizadas com solução salina peptonada a $0,1 \%$, posteriormente (diluição $10^{-1}$ ). A partir desta diluição foram obtidas as diluições de $10^{-2}$ e $10^{-3}$. A partir das diluições seriadas foram determinadas as unidades formadoras de colônia (UFC/g), após incubação a $37^{\circ} \mathrm{C}$, por 24 horas, em meio de cultura preparado em 6 placas com Agar cristal violeta vermelho neutro bile glicose (VRBG). Calculadas, de acordo com as diluições, as unidades formadoras de colônias de coloração vermelha, rodeadas ou não por halo de precipitação da bile presente no meio, com 0,5 a 2 mm de diâmetro.

\subsubsection{Coliformes totais e Salmonella sp.}

Os coliformes totais e fecais foram determinados pela técnica de fermentação em tubos múltiplos, no qual foi utilizado caldo Sulfato Triptose (LST) para o teste presuntivo e caldo verde brilhante no teste confirmativo para coliformes totais. O caldo Escherichia coli (EC) foi utilizado no teste confirmativo para coliformes fecais. A semeadura das amostras foi realizada por meio da adição de $1 \mathrm{ml}$ da amostra $10^{-1}, 10^{-2}$ e $10^{-3}$, da água coletada em $9 \mathrm{ml}$ de meio de cultura e os tubos com meio EC foram incubados a $45^{\circ} \mathrm{C}$, enquanto os demais foram incubados a $37{ }^{\circ} \mathrm{C}$ durante 24 / $48 \mathrm{~h}$.

Em $225 \mathrm{~mL}$ de Caldo de água peptonada tamponada a 1\%, foram homogeneizados $25 \mathrm{~g}$ de amostra, se seguido da incubação por 24 horas, a $37^{\circ} \mathrm{C}$. A seguir, transferiu-se $1 \mathrm{ml}$ do meio anterior para tubo contendo $10 \mathrm{ml}$ de Caldo Selenito Cistina e caldo Rappaport, incubando-o por 24 horas, a $41^{\circ} \mathrm{C}$. Quando é utilizada solução salina peptonada tamponada, esta favorece a manutenção do pH, evitando que as bactérias acompanhantes acidifiquem o meio, prejudicando a recuperação das células de Salmonella.

\subsection{Análise centesimal da farinha}

A composição centesimal da farinha foi realizada no Laboratório de Nutrição Animal e Bromatologia da Universidade Federal do Pará - Campus Castanhal, Faculdade de Medicina Veterinária. Todas as determinações foram realizadas em 
triplicata. As seguintes variáveis foram aferidas:

Umidade: a umidade foi determinada pela metodologia $\mathrm{n}^{\circ} 932.12$ da AOAC (1997), por secagem em estufa a $105^{\circ}$, durante 24 horas até peso constante.

Cinzas: foram determinadas pelo método gravimétrico, por calcinação de acordo com a metodologia $\mathrm{n}^{\circ} 938.08$ da AOAC (1997), em forno mufla a $550{ }^{\circ} \mathrm{C}$, por 8 horas.

Proteína: foi determinada pelo método Kjeldahl, através da determinação do nitrogênio total da amostra, aplicando o fator de correção 6,25 de acordo com a metodologia no 940.25 da AOAC (1997).

Lipídeos: o teor de lipídeos foi determinado por soxlet (TE - 044 TECNAL), por extração com éter de petróleo seguindo o método ${ }^{\circ}$ 948.22 da AOAC (1997).

Valor Calórico: foi determinado de acordo com os coeficientes de Atwater, que se aplicou através da somatória das médias de proteínas e carboidratos multiplicados por quatro e lipídios multiplicados por nove, de acordo com a equação:

\section{Valor Calórico $(\mathrm{kcal} / 100 \mathrm{~g})=[($ Proteína $\mathbf{x} 4)+($ carboidrato $\mathbf{x} 4)+($ lipídio x 9) $]$}

Carboidratos: A fração de carboidratos foi determinada pela expressão abaixo:

Valor de carboidratos $=100-(\%$ de umidade $+\%$ de cinzas $+\%$ de proteínas $+\%$ de lipídeos $)$.

\subsection{Análise de cor}

A cor da farinha foi determinada no sistema CIEL*a*b* em equipamento Chroma Meter CR-310 (iluminante C e ângulo $10^{\circ}$ ), através dos parâmetros: $\mathrm{L}^{*}$ (luminosidade), $\mathrm{a}^{*} \mathrm{e} \mathrm{b}^{*}$ (coordenadas de cromaticidade). Neste sistema, $\mathrm{L}^{*}$ indica a luminosidade $(0=$ preto e $100=$ branco $)$ e $\mathrm{a}^{*}$ e $\mathrm{b}^{*}$ indicam as direções que a cor pode assumir $\left(+\mathrm{a}^{*}=\right.$ vermelho e $-\mathrm{a}^{*}=$ verde; $+\mathrm{b}^{*}=$ amarelo $\mathrm{e}-\mathrm{b}^{*}=$ azul). $\mathrm{O}$ teste foi feito em triplicata e o equipamento foi previamente calibrado.

\section{Resultados}

\subsection{Rendimento}

O balanço de massas do processo desde o momento da colheita do caramujo até a obtenção da farinha é apresentado na Tabela 1.

Tabela 1 - Determinação do rendimento a partir de $1.000 \mathrm{~g}$ de animais.

\begin{tabular}{|c|c|c|c|}
\hline Fase & $\begin{array}{c}\text { Rendimento }(\%) \\
\text { Achatina fulica }\end{array}$ & $\begin{array}{l}\text { Rendimento }(\%) \\
\text { Achatina fulica }\end{array}$ & $\begin{array}{l}\text { Rendimento }(\%) \\
\text { Helix aspersas }\end{array}$ \\
\hline Animal vivo (em pé) & 100 & 100 & 100 \\
\hline Em jejum & 98,10 & 96,78 & 94,00 \\
\hline $\begin{array}{l}\text { Animal vivo sem baba } \\
\text { (muco) }\end{array}$ & 92,53 & $\mathrm{NE}$ & 73,10 \\
\hline $\begin{array}{l}\text { Animal morto após } \\
\text { tratamento térmico } 1\end{array}$ & 74,45 & 73,81 & 49,40 \\
\hline Animal sem a concha & 30,35 & 52,55 & 41,50 \\
\hline Farinha de carne & 7,42 & 12,11 & 10,70 \\
\hline
\end{tabular}

${ }^{1}$ Abate e hidratação. *Aquino (2013); ** Cabezas Garcia et al. (2011), NE= Não Extraído. Fonte: Autores.

\subsection{Análise microbiológica}

A quantidade de colônia de Enterobactérias e coliformes fecais estão evidenciadas nas tabelas 2 e 3 , respectivamente. 
Tabela 2 - Determinação de Enterobacterias nas amostras de carne in natura e cozida.

\begin{tabular}{lc}
\hline Amostra & Quantidade de colônia (UFC/g) \\
\hline Carne In natura. & $1,9 \times 10^{3}$ \\
Carne Cozida. & $<10^{3}$ \\
\hline
\end{tabular}

Fonte: Autores.

Tabela 3 - Análises microbiológicas na amostra de farinha de carne do animal.

\begin{tabular}{|c|c|c|c|}
\hline Amostra & Salmonella. & $\begin{array}{l}\text { Coliformes totais } \\
\text { (NMP/g) }\end{array}$ & $\begin{array}{c}\text { Coliformes fecais } \\
(\mathrm{NMP} / \mathrm{g})\end{array}$ \\
\hline Farinha de caracol & Ausência. & 93 & 93 \\
\hline
\end{tabular}

Fonte: Autores.

\subsection{Análise centesimal}

Para as análises bromatológicas da farinha de caramujo A. fulica (Tabela 4), foi utilizada como base de comparação, parâmetros de qualidade da farinha de peixe, uma vez que não existe dados referentes à farinha de caracol.

Tabela 4 - Análise centesimal da farinha de caramujo.

\begin{tabular}{lc}
\hline \multicolumn{1}{c}{ Determinação } & Resultado \\
\hline Umidade (\%) & $4,36 \pm 0,29$ \\
Proteína bruta (\%) & $61,41 \pm 2,91$ \\
Lipídeos (\%) & $6,59 \pm 1,33$ \\
Cinzas (\%) & $5,59 \pm 0,15$ \\
Carboidratos & 22,26 \\
Valor calórico (kcal/100g). & 339,99 \\
\hline
\end{tabular}

Fonte: Autores.

\subsection{Cor instrumental da farinha}

Os parâmetros de cor instrumental final da farinha produzida e embalada em saco de polietileno estão registrados na Tabela 5 .

Tabela 5 - Determinação da cor instrumental final da farinha de caramujo.

\begin{tabular}{lc}
\multicolumn{1}{c}{ Parâmetros de cor } & Resultado \\
\hline $\mathrm{L}^{*}$ (luminosidade) & 48,86 \\
$\mathrm{a}^{*}$ & 0,54 \\
$\mathrm{~b}^{*}$ & 14,00 \\
Croma (Força da cor) & 14,01 \\
Ângulo de tonalidade & $119^{\circ}$ \\
\hline
\end{tabular}

Fonte: Autores.

\section{Discussão}

Comparando o rendimento obtido com valor observado por Aquino (2013) para a mesma espécie realizada nesse trabalho e com o rendimento feito por Cabezas Garcia et al. (2011) com a espécie H. aspersas, verificou-se que o resultado foi 
similar até o cozimento do animal e retirada de concha. Percebeu-se uma perda maior em relação aos resultados reportados por Aquino (2013) quando foi retirada a carne da concha após cozida, isso possivelmente diminuiu o rendimento da farinha.

O jejum e a extração manual do muco foram responsáveis por uma perda de 7,47\% da massa inicial dos caracóis colhidos nos terrenos residenciais, enquanto o tratamento térmico dos caracóis indica que o abate e hidratação contribuiu para uma redução de $25,55 \%$ em relação ao produto inicial. A concha representou percentualmente uma massa de 59,23\% dos caramujos após extração da carne. E finalmente, o rendimento percentual da farinha da carne do animal foi 7,42\% em relação ao animal vivo.

Para a determinação de Salmonella o resultado obtido foi ausência em 25g. De acordo com Brasil (2001), a análise de Salmonella sp. é considerada um parâmetro de qualidade para farinhas em geral. Sua presença torna o alimento impróprio para o consumo. Já para moluscos secos e salgados a legislação pede um padrão para coliformes termotolerante ou a $45^{\circ} \mathrm{C}$ de $10^{2}$ ou (100 NMP/g), desta forma a farinha obtida encontra-se dentro do recomendado pela legislação. Esses resultados sugerem que os procedimentos higiênicos sanitários para a obtenção da farinha de caramujo foram eficientes.

Umidade aferida a partir de farinha de víscera escargot e aruá foi de 5,55\% e 3,18\% (Barboza, 2002), valores próximos ao encontrado no presente trabalho, que foi de $4,36 \%$. Esses valores ficaram bem abaixo do padrão exigido para farinha de peixe, que é de no máximo de $10 \%$. Já o parâmetro de qualidade para farinha de vísceras exigido pela lei é de no máximo $8 \%$, qualificando as três farinhas.

O valor para proteína bruta da farinha de caramujo foi de $61,41 \%$. Barboza (2002) elaborou farinha de víscera de escargot e aruá e obteve valores para proteína bruta de 57,09\% e 57,12\%, respectivamente. Considerando que a legislação requer um teor mínimo de $58 \%$ de proteína para farinha de vísceras, pode-se considerar que a farinha obtida é uma ótima fonte de proteína.

O teor de lipídeos da farinha de caramujo foi 6,59\% próximo do limite inferior do intervalo recomendado para farinha de peixe (8 a 11\%). Barboza (2002) obteve valores de lipídeos de 10,86\% e 5,20\%, respectivamente, para as farinhas de vísceras de escargot e aruá. Saldanha et al. (2001) fizeram a composição de ácidos graxos e apresentou 56,78\% de poliinsaturados, $15,54 \%$ de monoinsaturados e $23,25 \%$ de saturados. Os resultados mostraram que a carne de escargot apresentava-se com baixo teor de lipídios (2,45\%), mas destaca-se por ser uma fonte de ácidos graxos essenciais (18,49\% de ácido linoleico) e um alto teor de ácidos graxos poliinsaturados. Para cinzas, a porcentagem obtida na farinha de caramujo foi bem abaixo da farinha de peixe, que é menor que 15\%, ficando dentro do padrão exigido para farinha de peixe (MAPA, 1998).

$\mathrm{O}$ valor dos parâmetros de cor indica pouca intensidade de vermelho e média luminosidade. $\mathrm{O}$ valor do ângulo de tonalidade, que descreve o atributo pelo qual uma amostra é identificada como verde, amarelo, vermelho etc., é quantificado como um ângulo medido em graus (ângulo de tonalidade). Os valores do ângulo de tonalidade indicam a cor da amostra, onde um ângulo de tonalidade de $0^{\circ}$ coincide com vermelho, $90^{\circ}$ com amarelo, $180^{\circ}$ com verde e $270^{\circ}$ com azul (Little, 1975).

$\mathrm{O}$ valor de croma $\mathrm{C}^{*}$, que é a intensidade da cor de uma amostra percebida pelos seres humanos, encontrado nesta pesquisa, sugere que a intensidade da cor da farinha do presente estudo é pouco intensa. Já para o valor do ângulo de tonalidade, pode-se considerar como sendo de cor amarela tendendo ao verde (Little, 1975).

Estudos sugerem que parte da dieta normal de animais pode ser substituída for farinhas de caracol, considerando o conteúdo de proteína e perfil de aminoácidos desse insumo (Heuzé \& Tran, 2017). No caso específico da aquicultura, um nível de inclusão de $25 \%$ de farinha de caracol na dieta de juvenis de Heterobranchus bidorsalis, um peixe cultivado, melhorou significativamente o conteúdo de proteína bruta no corpo e a composição de aminoácidos totais (Imodagbe et al., 2020). Para alimentação de camarões cultivados, benefícios ainda maiores são observados. De acordo com Moss et al. (2018), a suplementação de farinha de caracol para a substituição total da farinha de lula e krill pode ser feita para melhorar o crescimento dos camarões kuruma juvenis (Marsupenaeus japonicus) e reduzir seus níveis de colesterol. 


\section{Conclusão}

A obtenção da farinha de caramujo apresenta pouco rendimento 7,42\%, porém o valor nutricional do produto, obtido através de composição centesimal, demonstra ser compensada pelo alto teor de proteína e carboidrato e baixo teor de lipídios e cor amarela de pouca intensidade. Às análises microbiológicas da farinha de carne do caramujo indicam que os processamentos tecnológicos adotados em neste trabalho (dieta hídrica, abate, manipulação, embalagem) parecem ser viáveis para a obtenção de farinha de carne em relação à qualidade sanitária. Com essas informações a carne do caramujo gigante africano apresenta potencial como matéria prima na utilização de ração animal. Os dados gerados nessa pesquisa em conjunto com a literatura sobre o uso de farinha de caramujo apontam para a importância de trabalhos como esse, tendo em vista que se apresenta como uma possibilidade de redução das populações invasoras do Caracol-Gigante-Africano, além de apontar uma resposta estratégica às preocupações econômicas e nutricionais acerca do uso de farinhas proteicas no cultivo de animais aquáticos para consumo humano.

\section{Referências}

Aquino, M. C. (2013). Caracterização química do caramujo africano (Achatina (Lissachatina) fulica (Bowdich, 1822) e avaliação dos efeitos do muco cutâneo em úlceras de córnea em coelhos (Oryctolagus cuniculus) / Maurício Carneiro Aquino. -. 94 f: il.

Barboza, S. H. R. (2002). Estudos tecnológicos comparativos da carne e subprodutos dos moluscos escargot (Achatina fulica) e aruá (Pomacea lineata) / Silvia Helena Romeiro Barboza.

Brasil. (2001). Resolução - RDC nº 12, de 02 de janeiro de2001. Aprova o regulamento técnico sobre padrões microbiológicos para alimentos. Diário Oficial da União, Brasília, DF, n.7 - E, 10 jan. 2001.

Cabezas G., Edward H., Aguilar, D. E. R., Herrera, R. L. Q. \& Gómez, G. G. (2011). Obtenção de farinha de caramujo terrestre (Helix aspersa sp.) e sua composição de aminoácidos como possível fonte de proteína em nutrição animal. XIII Encontro Latino-Americano de Iniciação Cientifica e IX Encontro Latino-Americano de Pós-graduação - Universidade do Paraíba.

CABI.org. Datasheet: Lissachatina fulica (giant African land snail). 2021. http://www-cabi.ez263.periodicos.capes.gov.br/isc/datasheet/2640\#19800571127.

Caldeira, R. L., Mendonça, C. L. G.F., Goveia, C. O., Lenzi, H. L., Graeff-Teixeira, C., Lima, W. S., Mota, E. M, Pecora, I. L, Medeiros, A. M. Z, Carvalho, O. S. First record of molluscs naturally infected with Angiostrongylus cantonensis (Chen, 1935) (Nematoda: Metastrongylidae) in Brazil. Mem. Inst. Oswaldo Cruz, 102(7): 887-889.

Campion, M. (1961). The structure and function of the cutaneous glands in Helix aspersa. Journal of Cell Science, 3(58), $195-216$.

Carvalho da Silva E, \& Omena E. P. Population dynamics and reproductive biology of Achatina fulica Bowdich, 1822 (Mollusca, Gastropoda) in SalvadorBahia. Biota Neotrop. 2014, 14(3): 1-11.

CLIMATE. (2021). Data Org. Clima Terra Alta. PT, climate data.org/location/44007/

Dioumande, M., Koussemon, M., Allou, K. V., \& Kamenan, A. (2008). Efeito do caramujo (Achatina fulica) refeição na produção de frangos e carne de qualidade sensorial. Pesquisa Pecuária de Desenvolvimento Rural. 20 (12).

FAO. (2012). O Estado do Mundo Pesca e Aquicultura. FAO Pescas e da Aquicultura. Department Alimentação e Agricultura Organizações das Nações Unidas.

FAO. (2014). O Estado do Mundo Pesca e Aquicultura. FAO Pescas e da Aquicultura. Department Alimentação e Agricultura Organizações das Nações Unidas.

Ferraz, J. (1999). O escargot criação e comercialização. Ícone.

Fontanilla I. K. C, Sta. Maria, I. M. P, Garcia, J. R. M, Ghate, H., Naggs, F., \& Wade, C. M. (2014). Restricted Genetic Variation in Populations of Achatina (Lissachatina) fulica outside of East Africa and the Indian Ocean Islands Points to the Indian Ocean Islands as the Earliest Known Common Source. PLoS ONE 9 (9): e105151.

Graeff-Teixeira, C. Expansão da Achatina fulica no Brasil e potencial aumento do risco para angiostrongilíase. Trans. Roy. Soc. Trop. Med. Hyg., 101: 743744.

Hayashi, C. Soares, C. M., \& Boscolo, V. R. (2000). Diferentes fontes protéicas em dietas para o caramujo gigante (Achatina fulica) na fase de crescimento. Revista Brasileira de Zootecnia, 29(6), 208-2086.

Heuzé, V., \& Tran, G. (2017). Apple snail as animal feed. Biology and management of invasive apple snails. Philipp Rice Res Inst, Muñoz, 369-385. 
Imodagbe, M. O., Abdullahi, S. A., Yusuf, A., Umar, R., Yusuf, L. A., Wada, Y. A., \& Lawal, A. (2020). Impact of Garden Snail (Limicolaria flammea) Meal as Fish meal Replacement on Whole-body Biochemical Composition in Juvenile Heterobranchus bidorsalis (Mari). Nigerian Journal of Animal Science and Technology (NJAST), 3(1), 69-79.

Kotangale, J. P. (2011). Giant African snail (Achatina fulica Bowdich). Journal of environmental science \& engineering, 53(3), 375-380.

Leão, T. C. C., Almeida, W. R., Dechoum, M., Ziller, S. R. (2001). Espécies Exóticas Invasoras no Nordeste do Brasil: Contextualização, Manejo e Políticas Públicas / Tarciso C. C. Leão, Walkíria Regina Almeida, Michele Dechoum, Sílvia Renate Ziller - Recife: Cepan, 2011.

Lorenzi, A. T. (2006.) Estudo colorimétrico e espectroscópico do muco de caracóis Achatina sp alimentado com ração acrescida de plantas medicinais. São Paulo.

Lowe, S., Browne, M., Boudjelas, S., \& Poorter, M. D. (2000). 100 of the World's Worst Invasive Alien Species: A selection from the Global Invasive Species Database. Aliens, 12.

MAPA. (2003). Ministério da Agricultura Pecuária e Abastecimento. Secretaria de defesa agropecuária. Instrução Normativa No 62 , de 26 de agosto.

Moreira, A. (2014). Morfologia. http://www.escargots.com.br/escargot.html.

Moss, A. S., Koshio, S., Ishikawa, M., Yokoyama, S., Nhu, T. H., Dawood, M. A., \& Wang, W. (2018). Replacement of squid and krill meal by snail meal (Buccinum striatissimum) in practical diets for juvenile of kuruma shrimp (Marsupenaeus japonicus). Aquaculture Research, 49(9), $3097-3106$.

Merino, G., Barange, M., Mullon, C., \& Rodwell, L. (2010). Impacts of global environmental change and aquaculture expansion on marine ecosystems. Global Environmental Change, 20(4), 586-596.

Oeterher, M. (1996). Relatório-Processamento de escargot. Departamento de Ciência Técnica e Agroinformática. ESALQ/USP.

Paiva, C. L. (2006). (Ed.). Achatina fulica (Moluscos): praga agrícola e ameaça à saúde pública no Brasil. Página lançada em 10 de maio de 1999 e atualizada em 25 de abril de 2004. http://www.geocities.com/lagopaiva/achat_tr.htm.

Portelinha, M. K. (2011). Substituição da farinha de peixe por fontes alternativas de proteína animal no cultivo de alevinos de peixe-rei (Odontesthes bonariensis). Dissertação (Mestrado) - Programa de Pós-Graduação em Zootecnia. Faculdade de Agronomia Eliseu Maciel . Universidade Federal de Pelotas. Pelotas.

Raut S. K, \& Barker G. M. (2002). Achatina fulica Bowdich and other Achatinidae as pests in tropical agriculture In: Barker GM, editor. Molluscs as Crop Pests. Wallingford, UK: CAB International, 55-114.

Rebelo Neto, P. (2013). Xavier. Piscicultura no Brasil tropical. Hermus, 153-156.

Ribas, J. (1986). Criação de caracóis - nova opção econômica brasileira. Nobel, 123p.

Rodrigues, M. V., Fonseca Júnior, Z. M, \& Monteiro, A. G. (2007). Análise do impacto socioambiental do caramujo africano no município de São Gonçalo (RJ). Forum Ambiental da Alta Paulista, Anais. v. III.

Saldanha, T., Gaspar, A., \& Santana, D. M. N. (2001). Composição centesimal da carne de escargot (Achatina fulica) criado em Iguape, SP. Higiene Alimentar.

Soares, C. M., Hayashi, C., \& Gonçalves, G.S. (1999). Exigência de proteína para o caramujo gigante (Achatina fulica) em fase de crescimento. Acta Scientiarum, 21 (3), 683-686.

Tacon, A. (1989). Nutrición y Alimentación de Peces y Camarones Cultivados. Manual de Capacitación. Documento preparado para el Proyecto GCP/RLA/102/ITA. Organización de las Naciones Unidas para la Agricultura y la Alimentación. Brasilia, Brasil.

Thiengo, S. C., Faraco, F. A., Salgado, N. C., Cowie, R. H., \& Fernandez, M. A. (2007). Rapid spread of an invasive snail in South America: the giant African snail, Achatina fulica, in Brasil. Biological Invasions, 9(6), 693-702.

Tsukamoto, Ricardo Y., \& Takahashi, Neuza S. (2015). Falta de proteína para ração: estrangulamento da aquicultura no Brasil? Revista Panorama da Aquicultura. Edição 14 novembro/dezembro, 1992. http://www.panoramadaaquicultura.com.br/paginas/revistas/14/Proteina.asp.

Yano, Y., Oikawa, H., \& Satomi, M. (2008). Reduction of lipids in fish meal prepared from fish waste by a yeast Yarrowia lipolytica. International Journal of Food Microbiology, 121: 302-307. 